www.jmscr.igmpublication.org

Impact Factor (SJIF): 6.379

Index Copernicus Value: 71.58

ISSN (e)-2347-176x ISSN (p) 2455-0450

crossref DOI: _https://dx.doi.org/10.18535/jmscr/v6i5.65

Journal Of Medical Science And Clinical Research

\title{
Assessment of spectrum of Chest Radiographic Manifestations of Legionnaires' Disease: A retrospective study
}

\author{
Authors \\ Dr Shishir Gupta ${ }^{1}$, Dr Shikha Saxena ${ }^{2}$ \\ ${ }^{1}$ Associate Professor Dept of Radiodiagnosis, TSM Medical College Lucknow \\ ${ }^{2}$ Assistant Professor Dept of Radiodiagnosis, Hind Institute of Medical Sciences Sitapur UP \\ Corresponding Author \\ Dr Shikha Saxena
}

Assistant Professor Dept of Radiodiagnosis, Hind Institute of Medical Sciences Sitapur UP, India

\begin{abstract}
Background: Legionnaires' disease is not always suspected because of its non-specific symptoms, and the diagnostic tests routinely available do not offer the desired sensitivity. However, effective antibiotics are available. Hence; we planned the present study to analyse the spectrum of radiographic findings in patients with Legionnaires' disease.

Materials \& Methods: We planned the present study to assess Chest Radiographic Manifestations of Legionnaires' Disease. A total of 30 patients were included in the present study. We obtained data records of the patients from the archives of the department of radio-diagnosis and recorded complete demographic and clinical details. Type and pattern of chest radiographic findings of all the patients were recorded. Data of only those patients were included in the present study in which microbiological and radiographic examination confirmed the diagnosis of Legionnaires' disease. Evaluation of all the results was done by SPSS software.

Results: Positive radiographic findings were observed in 86.7 percent of the patients. Patchy pattern of distribution predominated in the present study and was found to be present in 63.3 percent of the patient population. In 53.3 percent of the cases, unilobar distribution of the lesion occurred.

Conclusion: A variety of radiographic manifestations are exhibited by Legionnaire's disease patients.

Keywords: Chest radiograph, Legionnaire's disease.
\end{abstract}

\section{Introduction}

The term given to the severe pneumonia and systemic infection caused by Legionella bacteria is Legionnaires' disease. Over time, the prevalence of legionellosis or Legionnaires' disease has risen, which might indicate a greater awareness and reporting of the disease. Advances in microbiology have led to a better understanding of the ecological niches and pathogenesis of the condition. ${ }^{1-3}$ Legionnaires' disease is not always suspected because of its non-specific symptoms, and the diagnostic tests routinely available do not offer the desired sensitivity. However, effective antibiotics are available. ${ }^{4}$ The occurrence of large community outbreaks of Legionnaires' disease can be reduced with the adoption of guidelines for the proper maintenance of cooling towers and other aerosol-generating devices. ${ }^{5}$ Although there have been several reports on the radiographic features of individual types of pneumonia which have 
emphasised specific patterns, there have been few studies which have looked at comparative radiographic features of these common pneumonias, in particular legionnaires' disease. ${ }^{6-8}$ In the light of above mentioned data, we planned the present study to analyze the spectrum of radiographic findings in patients with Legionnaires' disease.

\section{Materials \& Methods}

We planned the present study in the department of radio-diagnosis of the medical institute. It included evaluation of Chest Radiographic Manifestations of Legionnaires' Disease. We obtained ethical approval from the ethical committee of the institution. The present study was a retrospective analysis. A total of 30 patients were included in the present study. We obtained data records of the patients from the archives of the department of radio-diagnosis and recorded complete demographic and clinical details. Type and pattern of chest radiographic findings of all the patients were recorded. Data of only those patients were included in the present study in which microbiological and radiographic examination confirmed the diagnosis of Legionnaires' disease, based on the criteria described previously in the literature. ${ }^{9}$ Description of the radiographic abnormalities was done as follows:

- Patchy,

- Confluent or

- Interstitial.
Data records were also reviewed for assessing the presence or absence of pleural effusion and cavitations. Experienced and certified radiologists were assigned for analysis of the chest radiographic findings. Evaluation of all the results was done by SPSS software. Chi- square test and univariate regression curve were used for assessment of level of significance.

\section{Results}

A total of 30 patients were included in the present study. Among theses 30, 19 patients were males while the remaining were females. More than 50 percent of the subjects of the presents study were of more than 56 years of age. Only 3.3 percent of the subjects of the present study were of less than 25 years of age. Positive radiographic findings were observed in 86.7 percent of the patients. Patchy pattern of distribution predominated in the present study and was found to be present in 63.3 percent of the patient population. In 53.3 percent of the cases, unilobar distribution of the lesion occurred.

Table 1: Demographic details of all the patients with Legionnaire's disease

\begin{tabular}{|l|c|c|}
\hline Age group (years) & No. of patients & Percentage \\
\hline Less than 25 & 1 & 3.3 \\
\hline $26-40$ & 5 & 16.7 \\
\hline $41-55$ & 7 & 23.3 \\
\hline 56 and above & 17 & 56.7 \\
\hline Total & 30 & 100 \\
\hline
\end{tabular}

Graph 1: Age-wise distribution of all the patients with Legionnaire's disease 
Graph 2: Gender-wise distribution of patients in the present study

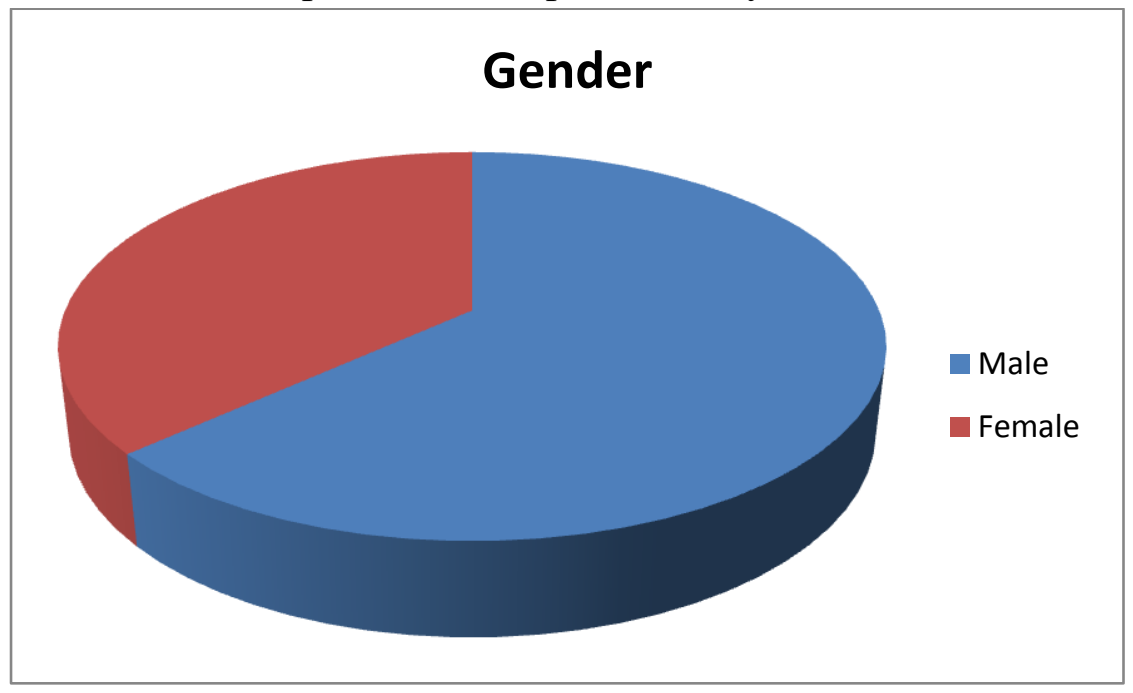

Table 2: Chest radiographic findings of Legionnaire's disease patients in the present study

\begin{tabular}{|l|c|c|c|}
\hline Parameter & & No. of patients & Percentage \\
\hline Findings & Negative & 4 & 13.3 \\
\cline { 2 - 4 } & Positive & 26 & 86.7 \\
\hline Pattern & Patchy & 19 & 63.3 \\
\cline { 2 - 4 } & Confluent & 4 & 13.3 \\
\cline { 2 - 4 } & Interstitial & 5 & 16.7 \\
\cline { 2 - 4 } & Mixed & 2 & 6.7 \\
\hline Distribution & Unilobar & 16 & 53.3 \\
\cline { 2 - 4 } & Multilobar & 10 & 33.3 \\
\cline { 2 - 4 } & Bilateral & 4 & 13.4 \\
\hline
\end{tabular}

Graph 3: Chest radiographic findings of Legionnaire's disease patients

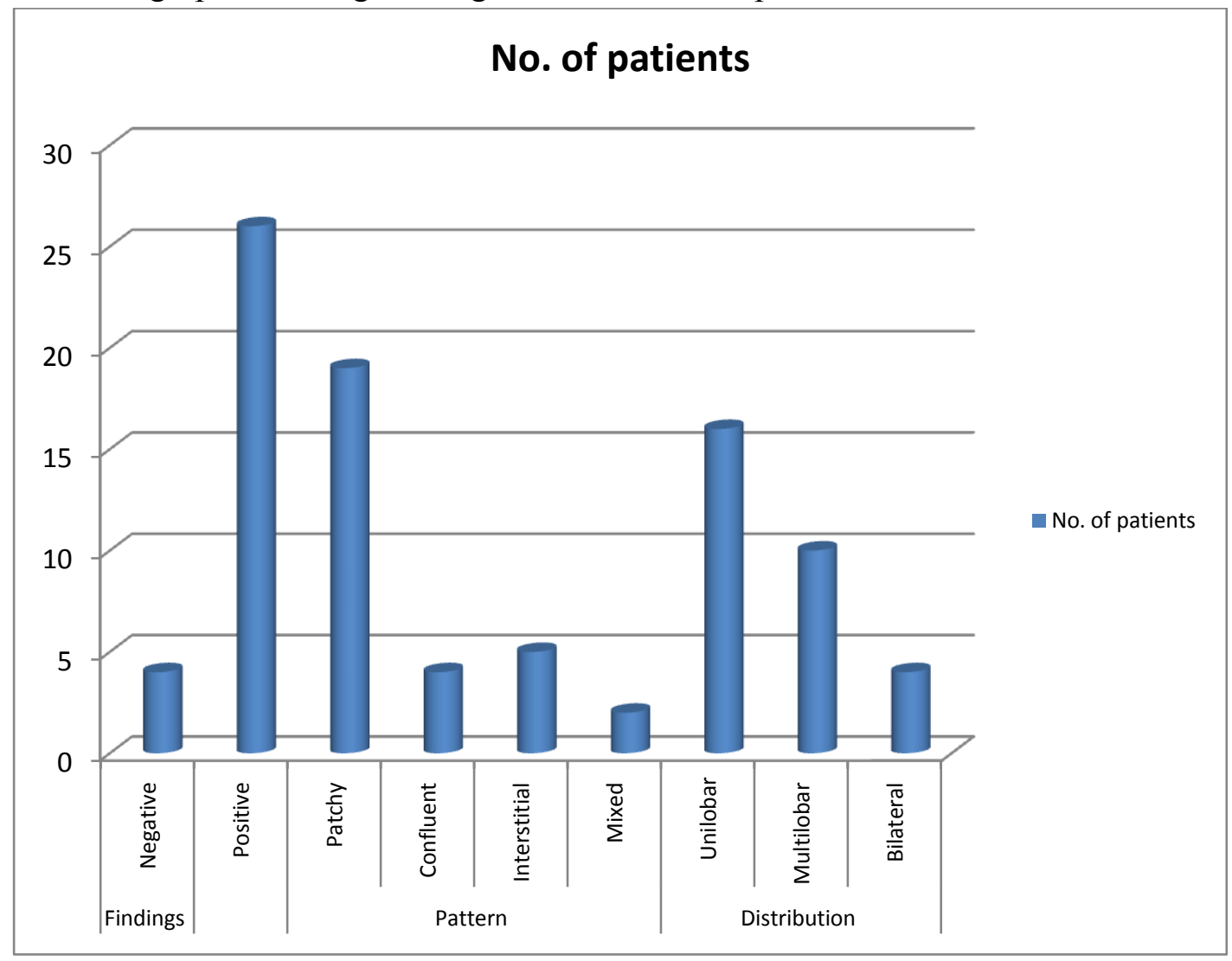




\section{Discussion}

In the present study, positive radiographic findings were observed in 86.7 percent of the patients. Patchy pattern of distribution predominated in the present study and was found to be present in 63.3 percent of the patient population. In 53.3 percent of the cases, unilobar distribution of the lesion occurred. Tan MJ et al studied the serial radiographic manifestations of Legionnaire's disease (LD) from the initial presentation on admission to recovery using strict criteria for the diagnosis of infection. The diagnosis of infection was based on the criteria of "definite" diagnosis as defined by the Ohio Community-Based Pneumonia Incidence Study Group report. The criteria included the isolation of the microorganism, the presence of a significant antibody rise, or the presence of Legionella antigen in the urine. Forty of 43 patients had admission radiographs interpreted as compatible with pneumonia. In spite of appropriate antimicrobial therapy, worsening of the infiltrates was found in more than half of the patients within the first week. Twenty-seven patients were observed to have pleural effusion during the course of hospitalization: 10 effusions were found on admission, another 14 developed during the first week, and 3 new effusions were discovered after the first week. Cavitation was found in only one patient. None of the patients had apical involvement. This study confirmed previous reports using less stringent etiologic diagnosis criteria that chest radiographic findings in Legionnaire's disease are not specific. ${ }^{13}$ Poirier R et al compare the tomographic presentation with that of community-acquired pneumonia caused by common bacteria other than Legionella pneumophila. From the 181 individuals affected in the outbreak, we obtained the chest radiographs of 159 individuals (mean $63 \pm 15$ years of age) for detailed analysis; 33 patients had a computed tomography (CT) scan performed during the course of their illness. In a case-control study, we compared the CT scans of patients with LD with those of patients who had received a diagnosis of community-acquired pneumonia caused by a pathogen other than Legionella and confirmed by chest CT scan. Overall, LD most often presented as an airspace consolidation involving 1 of the lower lobes. Pleural effusion and mediastinal adenopathies were apparent only in a minority, whereas no pneumothorax or cavitation was noted. We did not find any significant difference in chest CT scan findings in patients with LD vs those with community-acquired pneumonia from other bacterial origin. No radiological finding was clearly associated with an increased risk of intensive care unit admission or mortality. The early radiographic and tomographic manifestations of LD are nonspecific and similar to those found in community-acquired pneumonia from other bacterial origin. ${ }^{14}$

Zhang $\mathrm{Z}$ et al explored the chest radiographic characteristics of community-acquired Legionella pneumonia in the elderly. Serial chest radiographs obtained in 34 patients hospitalized with serologically proven Legionella pneumonia were retrospectively reviewed. Chest X-ray features of an aged group of $\geq 65$ years were assessed and compared with a non-aged group of $<65$ years old with regard to initial patterns and distributions of pulmonary abnormalities, accompanying signs, and progression. The most common initial presentation was a patchy alveolar infiltrate involving a single lobe, most often the lower lobe. There was no middle or lingular lobe involvement in the aged group patients, but bilateral pleural effusion was significantly more common in this group. In the aged group patients, radiographic progression following adequate therapy, despite a clinical response, was more often noted and the radiographs were less likely to have returned to the premorbid state at discharge, but the differences were not significant between the two groups. The discrepancy between imaging findings and clinical symptoms seems more prominent in community-acquired Legionella pneumonia in the elderly. ${ }^{15}$ 


\section{Conclusion}

Under the light of above, authors concluded that a variety of radiographic manifestations are exhibited by Legionnaire's disease patients. However; future studies are recommended.

\section{References}

1. Fraser DW, Tsai TR, Orenstein W, et al. Legionnaires' disease: description of an epidemic of pneumonia. N Engl J Med 1977; 297: 1189-97.

2. Edelstein PH. Legionella. In: Versalovic J, Carroll KC, Funke G, Jorgensen JH, Landry ML, Warnock DW, eds. Manual of clinical microbiology, 10th edn. Washington, DC: American Society of Microbiology Press, 2011: 770-85.

3. Jarraud S, Descours G, Ginevra C, Lina G, Etienne J. Identification of legionella in clinical samples. Methods MolBiol 2013; 954: 27-56.

4. Doebbeling BN, Wenzel RP. The epidemiology of Legionella pneumophila infections. Semin Respir Infect 1987; 2: 206-21.

5. Lück C, Fry NK, Helbig JH, Jarraud S, Harrison TG. Typing methods for legionella. Methods MolBiol 2013; 954: 119-48.

6. Joly JR, McKinney RM, Tobin JO, Bibb WF, Watkins ID, Ramsay D. Development of a standardized subgrouping scheme for Legionella pneumophilaserogroup 1 using monoclonal antibodies. J ClinMicrobiol 1986; 23: 768-71.

7. Helbig JH, Kurtz JB, Pastoris MC, Pelaz C, Lück PC. Antigenic lipopolysaccharide components of Legionella pneumophila recognized by monoclonal antibodies: possibilities and limitations for division of the species into serogroups. J ClinMicrobiol 1997; 35: 2841-45.
8. Dournon E, Bibb WF, Rajagopalan P, Desplaces N, McKinney RM. Monoclonal antibody reactivity as a virulence marker for Legionella pneumophilasero group 1 strains. J Infect Dis 1988; 157: 496-501.

9. Tan MJ1, Tan JS, Hamor RH, File TM Jr, Breiman RF. The radiologic manifestations of Legionnaire's disease. The Ohio Community-Based Pneumonia Incidence Study Group. Chest. 2000 Feb;117(2):398-403.

10. Zhang Z1, Liu X2, Chen L3, Qiu J3. Chest radiographic characteristics of communityacquired Legionella pneumonia in the elderly. Chin Med J (Engl). 2014;127 (12):2270-4.

11. Kim KW et al. Chest computed tomographic findings and clinical features of legionella pneumonia. J Comput Assist Tomogr. 2007 Nov-Dec;31(6):950-5.

12. Yagyu H1, Nakamura H, Tsuchida F, Sudou A, Kishi K, Oh-ishi S, Matsuoka T. Chest CT findings and clinical features in mild Legionella pneumonia. Intern Med. 2003 Jun;42(6):477-82.

13. Tan MJ1, Tan JS, Hamor RH, File TM Jr, Breiman RF. The radiologic manifestations of Legionnaire's disease. The Ohio Community-Based Pneumonia Incidence Study Group. Chest. 2000 Feb;117(2):398-403.

14. Poirier R1, Rodrigue J1, Villeneuve J2, Lacasse Y3. Early Radiographic and Tomographic Manifestations of Legionnaires' Disease. Can AssocRadiol J. 2017 Aug;68(3):328-333.

15. Zhang Z1, Liu X2, Chen L3, Qiu J3. Chest radiographic characteristics of communityacquired Legionella pneumonia in the elderly. Chin Med J (Engl). 2014;127(12):2270-4. 